\title{
Construção do saber médico: crítica ético-política
}

Elen $\mathrm{Nas}^{1}$, Rodrigo Siqueira-Batista ${ }^{2}$

1. Universidade Federal do Rio de Janeiro, Rio de Janeiro/RJ, Brasil. 2. Universidade Federal de Viçosa, Viçosa/MG, Brasil.

\section{Resumo}

Este texto é um comentário ao livro Natural, racional, social: razão médica e racionalidade científica moderna, de Madel T. Luz. Sua crítica à racionalidade e à metodologia científica baseia-se no reconhecimento de um quê ideológico nessas dimensões, delineado principalmente a partir da Revolução Industrial. As reflexões da autora buscam respostas para explicar a marginalização de outros modos de lidar com a realidade (com destaque para o vitalismo, cuja presença é marcante na homeopatia), que foram e ainda são atacados pelo modelo hegemônico instituído pela ciência moderna. Ressalta-se que a estética desempenha um papel importante na produção e disseminação do conhecimento, como base capaz de ampliar a visão para diferentes perspectivas de racionalidade e de elaboração ética.

Palavras-chave: Conhecimento. Homeopatia. Políticas de saúde.

\section{Resumen}

\section{Construcción del saber médico: crítica ético-política}

Este texto es un comentario al libro Natural, racional, social: razón médica y racionalidad científica moderna, de Madel T. Luz. Su crítica a la racionalidad y a la metodología científica se basa en el reconocimiento de un aspecto ideológico en estas dimensiones, delineado principalmente a partir de la Revolución Industrial. Las reflexiones de la autora buscan respuestas para explicar la marginalización de otros modos de hacer frente a la realidad (con destaque para el vitalismo, cuya presencia es destacada en la homeopatía), que fueron y aún son atacados por el modelo hegemónico instituido por la ciencia moderna. Se resalta que la estética desempeña un papel importante en la producción y difusión del conocimiento, como base capaz de ampliar la visión a diferentes perspectivas de racionalidad y elaboración ética.

Palabras clave: Conocimiento. Homeopatía. Política de salud.

\section{Abstract}

\section{Construction of medical knowledge: ethical-political criticism}

This article is a commentary on the book Natural, racional, social: razão médica e racionalidade científica moderna by Madel T. Luz. Her criticism of rationality and scientific methodology is based on recognizing an ideological aspect in these dimensions, outlined mainly from the Industrial Era. Her reflections seek answers to explain the marginalization of other ways of dealing with reality that were and remain under attack by the hegemonical model of modern science (with special attention to vitalism, a striking aspect of homeopathy). Aesthetics are crucial in the production and dissemination of knowledge as the basis to broaden the vision toward different perspectives of rationality and ethical elaboration.

Keywords: Knowledge. Homeopathy. Health Policy. 
Referência no pensamento contemporâneo na área da saúde, a obra Natural, racional, social: razão médica e racionalidade científica moderna, de Madel T. Luz ${ }^{1}$, relançada pela Editora Fiocruz em 2019, completou 30 anos desde sua primeira edição. Em pesquisa no Google Scholar, realizada em 8 de julho de 2018, consta que a versão em português do livro foi citada 682 vezes. A consulta foi repetida em diferentes datas, com resultados similares. A consideração de edições distintas do livro na contagem é responsável pelas variações numéricas. Ainda assim, o Google Scholar se referia apenas a duas edições específicas: uma de 2004, em português, e outra de 1997, em espanhol, enquanto pesquisas mais recentes, posteriores a 2019, contabilizam também a nova edição, de acesso livre.

Natural, racional, social reflete sobre paradigmas, vícios e resistências das práticas médicas a partir de uma perspectiva sociológica. A autora demonstra como as categorias, teorias e concepções da razão médica são biossociais e, portanto, não se guiam apenas por uma suposta neutralidade científica, mas também por um modo de enxergar o mundo que reduz as relações sociais à classificação normativa de sujeitos segundo polaridades binárias como normalidade-patologia, equilibrio-desvio, harmonia-perturbação, integridade-degenerescência ${ }^{2}$. De um ponto de vista crítico, Madel T. Luz expõe a racionalidade científica moderna ao longo de seis capítulos que serão brevemente comentados no presente ensaio: "Objetivos, bases e orientações: racionalidade científica e história" (Capítulo 1); "A construção da racionalidade científica moderna" (Capítulo 2); "Natureza e razão no tempo e no espaço mecânicos" (Capítulo 3); "A racionalização da sociedade no período clássico da Idade Moderna" (Capítulo 4); "A disciplina das doenças e a razão social; categorias médico-sociais no século XIX" (Capítulo 5); e "Razão médica e paixão política: mecanismo organicista $X$ vitalismo homeopata no século XIX" (Capítulo 6) ${ }^{1}$.

\section{Navegações: organização do livro}

No Capítulo 1, Madel T. Luz sustenta que a prática da medicina tem se pautado, também, em objetivar todos os aspectos humanos - a vida, o sofrimento, a morte -, e seu tecido se estabelece no discurso da racionalidade moderna, que não se atém a explicar a realidade, mas busca principalmente modelá-la. Trata-se de uma racionalidade que não se preocupa apenas com a origem e a causalidade dos fenômenos, mas que também, por meio de teorias antecipatórias, tende a construí-los, fabricá-los.

A autora destaca que a vida, o sofrimento, o adoecimento e a morte refletem as relações sociais, permitindo que indivíduos e grupos sociais vivam experiências distintas no cuidado com o corpo. Sendo assim, à medida que o sujeito moderno é moldado pelas forças que operam sobre seu corpo - o relógio, a máquina, as normas sociais, a vigilância de si, a vigilância do outro, a vigilância do Estado, a polícia, os rótulos -, a corporeidade se torna o alvo e, ao mesmo tempo, o centro dos acontecimentos. $O$ antropocentrismo da ciência moderna deixa as "leis divinas" de lado para focar no humano, seu corpo individual e social. Assim, as regras do contrato social são a extensão política da ciência. O mundo passa a ser explicado por regulamentações fundadas em princípios ético-filosóficos, com valores morais definidos de maneira distinta aos da religião. No pensamento moderno, a naturalização das normas aplicadas ao corpo faz parte de um plano de controle social em que a medicina se torna talvez a mais social das disciplinas modernas ${ }^{3}$.

A razão médica é, portanto, operada sob a lógica da disputa de hegemonia político-social, intrínseca ao modelo de racionalidade, que sustenta uma determinada ideologia de classe. Essa racionalidade representa estratégias de produção de discursos e políticas sociais aplicadas à medicina por meio de classificações que muitas vezes refletem conceitos e teorias divergentes e concorrentes na relação do estudo e da prática médica. As categorias e concepções que devem ser submetidas à análise crítica incluem "racional", "natural", "social", "vida", "saúde", "doença", "normalidade", "patologia", "equilíbrio" e "desvio", considerando que a razão e o "método científico" como norma fundamental para obtenção do conhecimento ou, de modo mais geral, como o modo de produção da verdade ${ }^{4}$, têm a pretensão de representar uma verdade destituída de intenções. Verdades são produzidas por obra do pensamento humano e não são exatamente características da natureza, ou da natureza humana, mas sim do olhar do Homo sapiens sobre a natureza e os fenômenos que observa. 
A ciência - como ferramenta de determinada ideologia de classe - reproduz pensamentos que influenciam métodos e práticas. Nessa esfera, a ideologia adquire contornos de um enunciado subliminar, presente nas políticas que atravessam os corpos dos sujeitos modernos, organizando-se em biopolíticas orquestradas por dispositivos de biopoder. A medicina é um desses dispositivos encarregados de manter a ordem social. Seus discursos disciplinares evocam uma ordem racionalizada, enquanto o método pretende sustentar que tal racionalização e todas as divisões construídas a partir dela fazem parte de uma ordem presente tanto na natureza como na estrutura dos corpos.

Quando se trata de epistemologia - aqui considerada como teoria do conhecimento -, não se pode esquecer que a linguagem é um desses dispositivos. Ela revela a cultura e sua poética. Como lembra Michel Foucault, conhecer é interpretar sinais, e o jogo do signo busca o similar como referência para o discurso. Diz ele: a linguagem não é aquilo que é por ter um sentido 5 . Com efeito, a naturalização de certas premissas na esfera do conhecimento falha ao não considerar os contextos culturais e sociais, assim como o universo de crenças e afinidades dos cientistas no momento em que formulam suas teorias. A universalização de saberes - tidos como neutros em relação à cultura - faz com que eles se tornem dispositivos de poder.

No Capítulo 2, Madel T. Luz lembra que a racionalidade definidora da modernidade começa a ser gestada no século XVI, no período da chamada "revolução científica". A necessária ruptura com a visão de mundo que antecede essa revolução reflete não apenas profundas transformações nas relações sociais, como também faz emergir o indivíduo autônomo, "independente", capaz de transformar o contexto pessoal e social criativamente.

O humanismo renascentista torna-se antropocentrismo humanista, e o homem passa a se enxergar como proprietário da natureza. O colonizador e o conquistador deixam de ser "aventureiros" ou "saqueadores" para ganhar um novo status social, amparado num novo paradigma em que o processo decisório se restringe ao julgamento humano: A existência "objetiva" $e$ "independente" da natureza em face do mundo humano é, desta forma, condição epistemológica e ontológica para que o homem possa conhecê-la e moldá-la, para que coloque sobre o reino da natureza o selo de sua ordem. A ordem da Razãob.
O experimentalismo faz parte do método científico moderno, que é ao mesmo tempo exploratório e interventor, pois cria instrumentos de observação empírica, iniciando a era da tecnologia da ciência ${ }^{7}$. Interessante notar que tal método cria disciplinas que buscam isolar fenômenos para melhor compreendê-los, reforçando a alienação do todo ${ }^{8}$, o que pouco a pouco se reflete em toda a estrutura e organização da sociedade industrial.

A ruptura epistemológica se reflete também na separação entre o ser e a natureza. Categorias bipolares reforçam separações excludentes, como se os contrários e a anulação de um pelo outro fossem naturais. Assim, há não apenas "natureza-homem", "qualidade-quantidade", "objeto-sujeito", "corpo-alma", "sentidos-razão", "organismo-mente", "paixões-vontade", "forma-matéria", entre outros, mas a própria razão dessas dicotomias é multiplicada nos modos do fazer científico, em seus métodos e em toda teoria do conhecimento. Ademais, a racionalização da vida fabrica enunciados com verdades específicas, que reforçam regras de produção e valores considerados mais importantes dentro desse modelo de racionalidade. Trata-se de verdades comunicadas pelas regras do método e que influenciarão a construção de novas regras com o objetivo de guiar o indivíduo pela vida moderna. De fato, Descartes dá forma de "conceitos" aos traços mecanicista, dualista e quantitativista da racionalidade moderna".

O mecanicismo - visão que concebe o mundo como um grande mecanismo - influenciará a organização das disciplinas e, embora tenha característica experimental, inventiva e construtora de realidades a partir de abstrações do imaginário, a crença em uma razão pura - capaz de produzir conhecimentos por meio de um método científico infalível dogmatiza esse método a ponto de canonizá-lo como procedimento universal a ser adotado para purificar os conceitos de suas fontes imaginárias. A razão moderna "imagina" a si mesma como imagina o mundo; isto é, como "máquina", como engenho ${ }^{10}$. O racionalismo de inspiração cartesiana organiza o método a ser aplicado às ciências e a busca da verdade para esse conhecimento em geral. Porém, um dos problemas de transformar um método em dogma ${ }^{4}$ é que a repetição de modelos teóricos em diferentes disciplinas, em vez de gerar unidade, gera o fenômeno da dissociação, pelo qual o conhecimento racional científico se distancia pouco ou nada - de compreensões metafísicas do mundo. 
A racionalidade moderna reaviva a alegoria do conhecimento "puro" das formas puras, da República de Platão ${ }^{12}$, aspecto que Madel T. Luz tematiza no Capítulo 3, no qual discute a natureza e a razão no tempo e no espaço mecânicos. Como a idealização das formas puras são traduzidas na Idade Moderna pela compreensão sobre a matéria e as dificuldades de lidar com o não mensurável, as ciências da natureza não somente buscaram a exatidão, como também, sempre que necessário e possível, procuraram ajustar os fenômenos às compreensões que lhe eram mais familiares, a fim de ter mais controle sobre processos e desdobramentos. Desde esta perspectiva, o universo-máquina, mensurado, automatizado, operado e comandado pelo Homo sapiens, faz parte do ideal mecanicista da ciência moderna, o qual, mais tarde, é também traduzido para as ciências humanas por meio do positivismo: a ordem, a exatidão e a neutralidade científica são categorias articuladas ao método, o único método supostamente capaz de levar o cientista a encontrar a verdade.

A síntese epistemológica dos teóricos - filósofos e cientistas da era moderna - traduz-se no modelo explicativo (mecanicista), no método (experimentalista e dedutivista) e na linguagem (matematizante). Essa síntese permanece hegemônica na compreensão, criação e construção de tecnologias, tanto no trabalho como nas artes, na moral e nos costumes. Assim, campos disciplinares como a Medicina, em diversos dos seus ramos, adotaram o modelo mecanicista, elaborando conceitos e teorias sobre sua base metodológica e epistemológica ${ }^{13}$. Ademais, se as descobertas das ciências tinham um efeito prático de mudança qualitativa na vida social e econômica ${ }^{14}$, sua racionalidade permanece voltada à conquista e ao controle do mundo. Desse modo, afirma a autora, sociedade e razão fundem-se no pacto que se denominará "contrato social", em que a ciência se torna a teologia da presente época.

o Capítulo 4 analisa o período histórico clássico, no qual se constituem as bases da racionalidade moderna. Madel T. Luz lembra que a racionalização dos costumes e das mentalidades na sociedade clássica não começa pela filosofia natural, mas pela moral resultante da religião cristã ${ }^{15}$, e que as ordens religiosas foram formadoras morais que conduziram à construção da ética moderna. Nesse contexto, o sujeito social se torna objeto de um projeto biopolítico a ser operado nas relações sociais, e a Igreja é uma dentre outras instituições de controle moral onde as relações de biopoder se estabelecem.

Cabe destacar que a racionalização moral é parte de uma construção estética, de uma visão de mundo centrada em "categorias ideais" que delineiam códigos disciplinares embasados em uma filosofia política que, tradicionalmente, marginaliza os sentidos e separa praxis e aisthesis. O mundo material comandado e explicado pela razão define prioridades com base em suas crenças pragmáticas, hierárquicas e distintivas. Assim, segundo Luz, a sensualidade é um inimigo das duas razões: da razão científica natural e da razão da moralidade cristã, religiosa ou laica ${ }^{16}$. A autora, porém, afirma: se a arte não "diz" a verdade, "expressa" realidades ${ }^{17}$. Tem-se, desse modo, um contraponto na moral cujo propósito é o controle espiritual da sociedade: a estética é o mecanismo de transmissão que converte a teoria em prática. Ela traduz as ideias da ética para a vida cotidiana por meio dos sentimentos e dos sentidos, transformando a ideologia em prática social espontânea ${ }^{18}$.

No Capítulo 5, Madel T. Luz discute conceitos que moldam as práticas médicas, como o privilégio da ciência sobre a arte, cujas explicações se estendem às condições clínicas. Um exemplo disso é o discurso sobre a autoimunidade como plano de ação significativa para construir e manter os limites entre eu e outro, nos domínios cruciais do normal e do patológico ${ }^{19}$. Ademais, as subdivisões como anatomia, fisiologia e patologia fazem parte dos métodos de observação que agregam ao projeto disciplinar o controle dos corpos por categorias de doenças. O poder exercido sobre os corpos determina quais deles podem estar livres ou confinados, assim como mede e determina quão livres esses corpos podem ser. Os limites de liberdade de um corpo são definidos a partir de sua localização existencial: status social, local de moradia, condições de vida e de trabalho. A percepção da doença dissociada das condições sociais torna totalmente ficcional a metodologia aplicada às ciências médicas. Ainda nesse capítulo, a autora busca fontes representativas de outros tipos de racionalidade médica, como aquelas que percebem a doença como uma resposta do corpo aos estímulos recebidos por meio de experiências sensoriais. Ela lembra que o positivismo, o evolucionismo e o mecanicismo são categorias biossociais que refletem ordenações hierárquicas em toda a base do conhecimento. 
Ao final do livro, no Capítulo 6, Madel T. Luz fala do caráter ativista intrínseco ao vitalismo homeopata no século XIX, que se contrapõe ao mecanicismo organicista típico das teorias hegemônicas. A autora destaca que o debate epistemológico - especialmente ético, e quiçá estético concernente à medicina dificilmente avançará sem a avaliação cuidadosa da batalha política alopatia versus homeopatia, que deveria passar pela percepção dessas diferenças e dessa competição teórica $^{20}$. Com efeito, as estratégias de desmoralização sistemática de práticas e compreensões não alopáticas sobre como tratar doenças e curá-las merecem ser eticamente questionadas, pois, em última análise, representam disputas de poder e de mercado próprias à lógica do capitalismo tardio $^{21}$. Tais questões se inscrevem na compreensão de que a doença - uma abstração, um modelo para dar sentido aos achados clínicos ${ }^{21}$ - pode ser associada à compreensão do empirista David Hume de que a razão é também uma espécie de sentimento, que tem a imaginação como juiz ${ }^{18}$.

A ideia de que o racional é "objetivo" leva a tratar sintomas em separado e descartar tudo o que seja entendido como "subjetivo" e "vago". Nesses termos, para o vitalismo homeopático, não se trata de "curar" por "inflamações de dispositivos", mas da "arte da cura", pois há beleza no ato de curar, e faz parte do território da estética o que se refere à vida sensível, à apreensão de informações pelos sentidos. O corpo afetivo que dialoga com o mundo por sintomas e sinais é um corpo que cria o que lhe é possível, segundo os estímulos do seu meio.

\section{Considerações finais}

O trabalho de Madel T. Luz soma-se aos questionamentos dirigidos ao saber fazer da medicina ${ }^{22}$, que, como prática social, não é neutra, como tampouco o são seus conceitos e métodos. O livro em pauta apresenta a construção do saber médico em uma perspectiva crítica, sociológica e histórica. Entretanto, a partir do conhecimento da crítica e da existência de outras maneiras (racionalidades) de buscar soluções para os problemas humanos, o profissional da saúde poderá ampliar sua consciência e contribuir para potenciais mudanças. Desse modo, com rigor acadêmico e de maneira original, Natural, racional, social: razão médica e racionalidade científica moderna acena para a possibilidade de um trabalho indissociável da tríade ética, estética e epistemologia, reconhecendo que a potência originária da medicina é precisamente a arte de cuidar.

\section{Referências}

1. Luz MT. Natural, racional, social: razão médica e racionalidade científica moderna [Internet]. Rio de Janeiro: Fiocruz; 2019. Disponível: https://bit.ly/3t5Eds7

2. Luz MT. Op. cit. p. 39.

3. Luz MT. Op. cit. p. 47.

4. Luz MT. Op cit. p. 49.

5. Foucault M. As palavras e as coisas. São Paulo: Martins Fontes [Internet]; 2000 [acesso 10 maio 2021]. Disponível: https://bit.ly/3hla2v5

6. Luz MT. Op cit. p. 60.

7. Luz MT. Op cit. p. 62.

8. Santos BS. Um discurso sobre as ciências. $7^{\text {a }}$ ed. São Paulo: Cortez; 2010.

9. Luz MT. Op cit. p. 70.

10. Luz MT. Op cit. p. 72.

11. Feyerabend PK. Contra o método. Rio de Janeiro: Francisco Alves; 1989.

12. Luz MT. Op cit. p. 71.

13. Luz MT. Op cit. p. 84. 
14. Luz MT. Op cit. p. 85.

15. Luz MT. Op cit. p. 94.

16. Luz MT. Op cit. p. 97.

17. Luz MT. Op cit. p. 98.

18. Eagleton T. A ideologia da estética. Rio de Janeiro: Zahar; 1993.

19. Haraway D. Simians, cyborgs, and women: the reinvention of nature. New York: Routledge; 1991.

20. Luz MT. Op cit. p. 168.

21. Siqueira-Batista R, Gomes AP, Albuquerque VS, Cavalcanti FOL, Cotta RMM. Educação e competências para o SUS: é possível pensar alternativas à(s) lógica(s) do capitalismo tardio? Ciênc Saúde Coletiva [Internet]. 2013 [acesso 12 jan 2021];18(1):150-70. DOI: 10.1590/S1413-81232013000100017

22. Siqueira-Batista R. Conhecimento e saúde: entre ciência e arte. In: Rego S, Palácios M. Comitês de ética em pesquisa: teoria e prática. Rio de Janeiro: Editora Fiocruz; 2012. p. 53-70.

Elen Nas - Doutora - elennas@ufrj.br

(D) 0000-0002-6275-2799

Rodrigo Siqueira-Batista - Doutor - rsbatista@ufv.br

(D) 0000-0002-3661-1570

Correspondência

Elen C. Carvalho Nascimento - Universidade Federal do Rio de Janeiro.

Campus Praia Vermelha. Rua Venceslau Brás, 71, Botafogo CEP 22290-140. Rio de Janeiro/RJ, Brasil.

Participação dos autores

Elen Nas redigiu o texto, o qual foi revisto criticamente por Rodrigo Siqueira-Batista. Ambos autores aprovaram a versão final do manuscrito.

Recebido: 15.2 .2020

Revisado: 20.4 .2021

Aprovado: 22.4 .2021 